\title{
Inclined Rope Reeving Systems
}

\author{
Stefan Vöth ${ }^{1, *}$ \\ ${ }^{1}$ Lifting Technology Centre, Technische Hochschule Georg Agricola, Bochum, Germany
}

\begin{abstract}
Main part of crane systems in general and hoisting systems especially are rope-reeving systems. They are used to reduce the loading on the rope itself and on the following parts in the hoist drive. In order to transfer the performance required the reduced loading has to be compensated by higher speeds. General standard are reeving systems with just vertical rope orientation. They have advantages, as they are not difficult to plan, to build and to operate. On the other hand, they comprise disadvantages as well. One main disadvantage of vertical rope orientation is the tendency to load sway.
\end{abstract}

\section{Initial Situation}

Load sway leads to difficulties in load handling, to impact on crane functionality, to less precise load positioning and under circumstances even to hazardous operation [1-3].

There are different opportunities to decrease load sway. A common path is to implement control systems. Either with feedback systems or without feedback systems they control the crane movement with the target of load sway reduction. By nature, such control systems override external crane control signals. Due to this application has to be discussed. Furthermore, the nature of sensors, wiring and processors in relation to the environment may to be considered.

Another option to decrease load sway is to implement rope reeving systems including a non-vertical rope orientation. Such reeving systems are able to create horizontal forces on the load able to stabilize load position and thus to prevent load sway. Basically, a rope reeving system already exists and planning inclined rope parts seems to be a small effort. In fact, such reeving systems create modified properties to the reeving systems, which are content of following considerations. Hoist with 2/1 reeving system is shown in Fig. 1.

\footnotetext{
* Corresponding author: stefan.voeth@thga.de
} 


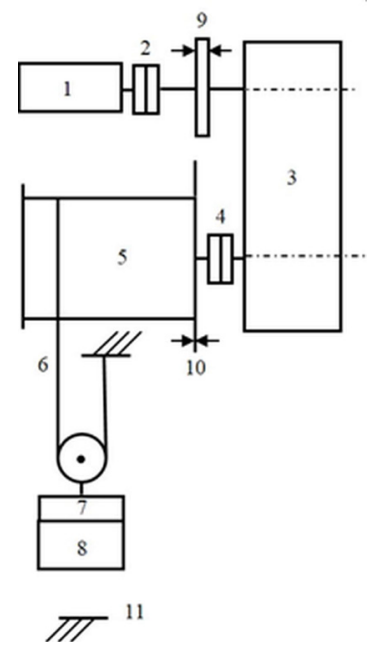

Fig. 1. Hoist with 2/1 reeving system: 1 Motor, 2 Motor coupling, 3 Gearing, 4 Drum coupling, 5 Drum, 6 Rope drive, 7 Load attachment device, 8 Load, 9 Motor brake, 10 Drum brake, 11 Ground.

\section{Arrangement}

Maybe the simplest reeving system is a $2 / 1$ reeving. The load is supported by two rope parts. One rope (the rope) is wind up on the rope drum. With vertical rope orientation this reeving system comprises just vertical rope force acting, incorporation the disadvantages mentioned. Also, quite common are 4/1 (Fig 2) reeving and 8/2 reeving, also equipped with ropes acting just vertically.

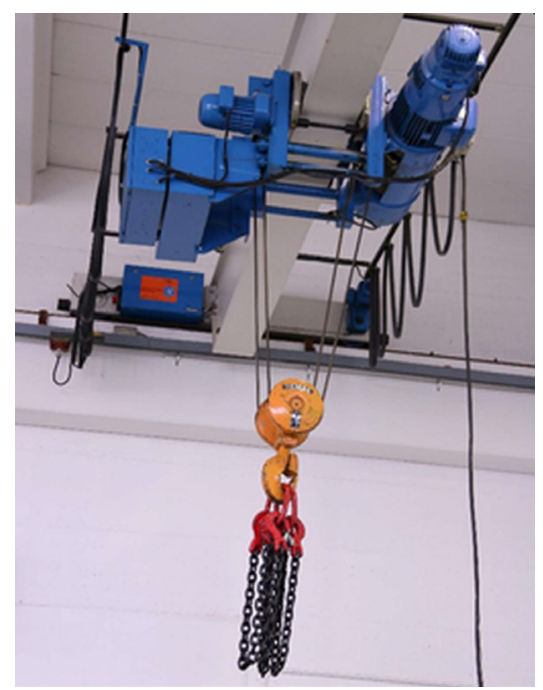

Fig. 2. Rope hoist with $4 / 1$ reeving system. 
More or less the same applies to chain hoists (Fig. 3). As they are applied in less applications with less relevance to the aspects pointed out, they are not in focus here.

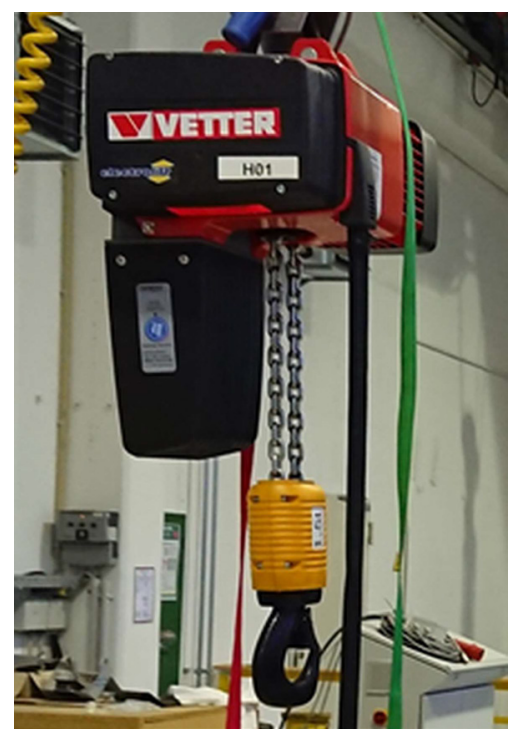

Fig. 3. Chain hoist with $2 / 1$ reeving system.

This $2 / 1$ reeving may be modified by relocation of the hinge point aside (Fig.4). This modification results in a vertical rope part and a non-vertical rope part. As the non-vertical rope part results in a horizontal force on the bottom block, the bottom block tends to find a new position in horizontal direction. The new horizontal position is associated with two nonvertical rope parts. The resulting two horizontal forces are in equilibrium. If the hinge point and the rope drum are positioned not at same height, this arrangement leads to horizontal load movement during lifting. In detail this is true even when the hinge point and the rope drum are positioned at same height.

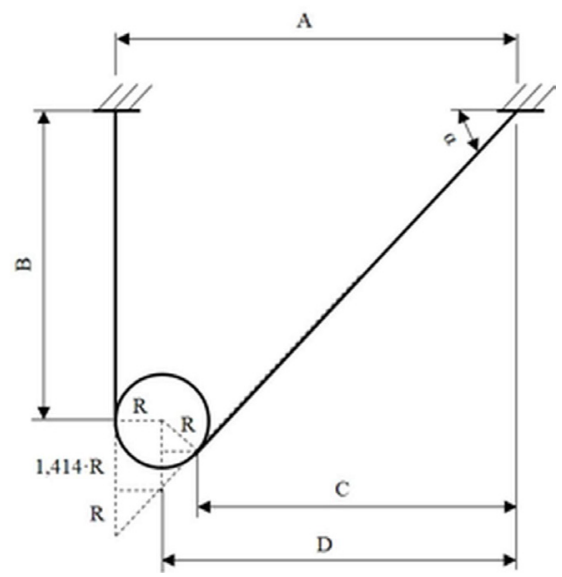

Fig. 4. 2/1 reeving with relocated hinge point. 
To prevent the outcomes of the relocation of the hinge point, the system is completed by a copy of the reeving system discussed so far. The copy is a copy of the original, mirrored at the vertical axis. Result is a system consisting of two $2 / 1$ reevings, a $4 / 2$ reeving. As the second reeving was mirrored, the first reeving produces a horizontal force to the right on the bottom block in its initial position, the second reeving produces a horizontal force to the left on the bottom block in its initial position. As both bottom blocks are connected to the same traverse, the horizontal forces are covered by compression in the traverse. This coverage of the horizontal forces prevents a horizontal movement of the bottom blocks. The lifting path of the load is just vertical.

Result is a reeving system with a strict vertical load path comprising non-vertical rope parts and horizontal forces acting on the load attachment device, likely to stabilize the horizontal position of the load.

\section{Properties of Vertical Rope Reeving Systems}

Important properties of reeving systems are the ratio $i_{R D}$ and the stiffness $c_{R D}$. For vertical rope reeving systems, the situation is quite simple out of an engineering point of view.

Ratio:

For a $\mathrm{m} / \mathrm{n}$ reeving the rope drive comprises a ratio of

$$
\begin{aligned}
i_{R D} & =\frac{m_{R D}}{n_{R D}} \\
i_{R D} & =\text { const } .
\end{aligned}
$$

The rope force is smaller than the load suspended at the rope drive by factor $i_{R D}$. The lifting speed is smaller than the rope wind up speed at the drum also by factor $i_{R D}$. The ratio of the rope drive $i_{R D}$ is not changing during lifting at all.

Stiffness:

For a $\mathrm{m} / \mathrm{n}$ reeving the rope drive comprises a stiffness of

$$
c_{R D}=m_{R D} \cdot \frac{f_{R} \cdot E_{R} \cdot A_{R}}{L_{R D}}
$$

With the relative rope stiffness

$$
c_{R, r e l}=f_{R} \cdot E_{R} \cdot A_{R}
$$

The stiffness of the rope drive just changes with the lifting position and the associated rope part length $\mathrm{L}_{\mathrm{RD}}$.

$$
C_{R D} \sim \frac{1}{L_{R D}}
$$

As all rope forces act vertically, the stiffness of the bottom block clamping is almost not existent.

$$
c_{R D, h o r} \approx 0
$$




\section{Properties of Inclined Rope Reeving Systems}

The geometry of the inclined rope reeving system varies with the lifting position. Due to this, properties of the inclined rope reeving system as ratio and stiffness change over lifting height. Ratio:

As not all rope parts are vertical, the ratio of the rope drive does not just depend on the number of load bearing rope parts $\mathrm{m}_{\mathrm{RD}}$ and the number of ropes running on drum $\mathrm{n}_{\mathrm{RD}}$. The ratio also depends on the inclination of the non-vertical rope parts. And the inclination in turn depends on the present lifting height.

Stiffness:

As not all rope parts are vertical, the stiffness of the rope drive does not just depend on the number of load bearing rope parts $\mathrm{m}_{\mathrm{RD}}$ and the number of ropes running on drum $\mathrm{n}_{\mathrm{RD}}$. The stiffness also depends on the inclination of the non-vertical rope parts. And the inclination in turn depends on the present lifting height.

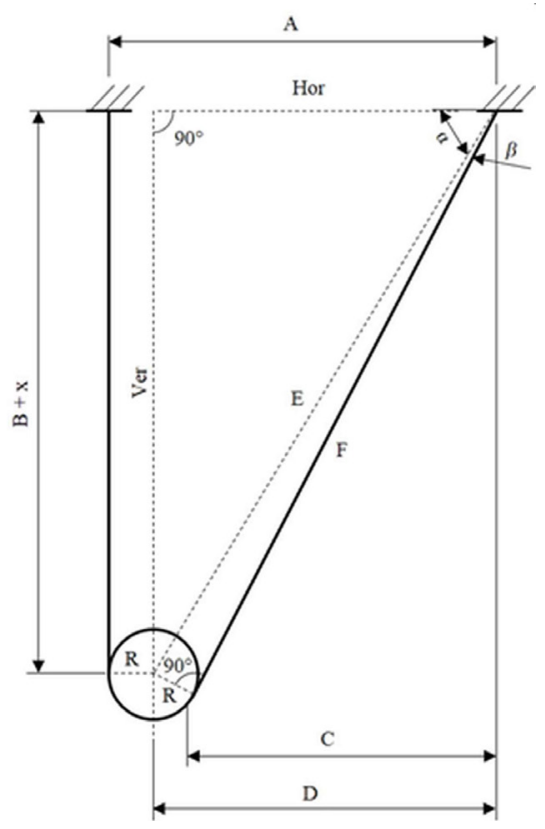

Fig. 5. 2/1 reeving with relocated hinge point at modified lifting position.

\section{Outlook}

The consideration of rope reeving properties is part of current work. Cooperations and contributions are welcome.

Aspects of work are on the ratio of the rope drive, the vertical stiffness of the rope drive and the horizontal stiffness of the rope drive.

\section{Symbols and Indices}

c Stiffness

f Filling factor

i Ratio 


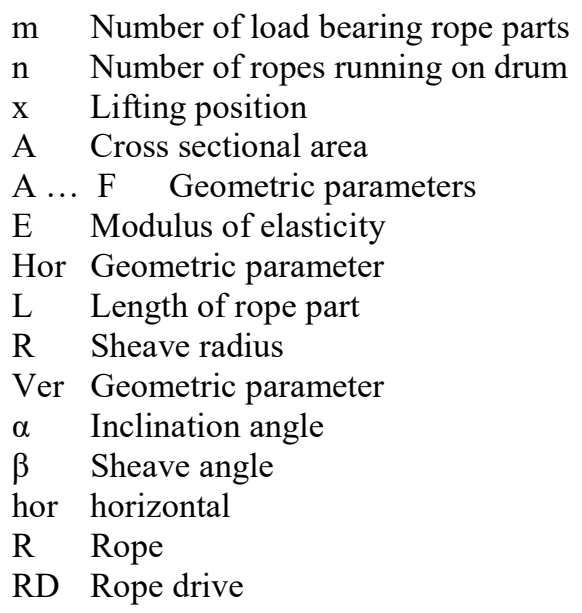

\section{References}

1. J. Zhao, Z.Su, Y. Cheng, J. Wan, L. Qiao, IOP Conf. Ser.: Earth Environ. Sci. 693, 012109 (2021)

2. A. Kyllingstad, A study oft he reeving efficiency and inertia of drawworks (IADC/SPE International Drilling Conference and Exhibition, Galveston, Texas, USA, 2020)

3. S. Vöth, V. Bogdanov, D. Pomazov, Modeling of Efficiencies on Basis of Power Flow Directions using Modelica on the Example of Hoisting Systems (Safety and Availability of Cranes Project, Bochum, 2020) 